\title{
SUPERVISI KUNJUNGAN KELAS UNTUK MENINGKATKAN KEMAMPUAN GURU DALAM MENGAJAR DENGAN MENGGUNAKAN MODEL KOOPERATIF
}

\author{
Nuraisah \\ naisah527@gmail.com \\ SD Negeri 011 Pondok Gelugur, Indragiri Hulu, Indonesia
}

\begin{abstract}
This research is motivated by the still weak competence of teachers in making learning implementation plans, implementing learning processes, and implementing learning evaluations. The purpose of this study is to improve teacher competency by using supervision of class visits to the application of cooperative models in learning. This research was conducted at 011 Pondok Gelugur Elementary School with a total of 6 teachers. The type of research to be carried out is the School Action Research (PTS) which is focused in an effort to change the current real conditions towards the expected. The results showed the teacher's competence in preparing the RPP in the first cycle got a value of 73.3 with enough categories while in the second cycle increased to 87.6 with a very good category. Competence in the implementation of the learning process in the first cycle got an average value of 75.4 good categories while in the second cycle increased to 86.0 with a very good category. The competence of implementing learning evaluation in the first cycle got an average value of 74.4 with enough categories while in the second cycle increased to 88.0 with a very good category. It can be concluded with the supervision of class visits can improve teacher competency in learning by applying a cooperative model in SD Negeri 011 Pondok Gelugur.
\end{abstract}

Keywords: supervising class visits, cooperative models, teacher competencies

\section{ABSTRAK}

Penelitian ini dilatarbelakangi oleh masih lemahnya kompetensi guru dalam pembuatan rencana pelaksanaan pembelajaran, pelaksanaan proses pembelajaran, dan pelaksanaan evaluasi pembelajaran. Tujuan penelitian ini adalah untuk meningkatkan kompetensi guru dengan menggunakan supervisi kunjungan kelas terhadap penerapan model kooperatif dalam pembelajaran. Penelitian ini dilaksanakan di SD Negeri 011 Pondok Gelugur dengan jumlah guru sebanyak 6 orang. Jenis penelitian yang akan dilaksanakan adalah penelitian tindakan sekolah (PTS) yang terfokus dalam upaya merubah kondisi nyata terkini kearah yang diharapkan. Hasil penelitian menunjukan kompetensi guru dalam menyusun RPP pada siklus I mendapat nilai sebesar 73,3 dengan kategori cukup sedangkan pada siklus II meningkat menjadi 87,6 dengan kategori sangat baik. Kompetensi pelaksanaan proses pembelajaran pada siklus I mendapat nilai rata-rata sebesar 75,4 kategori baik sedangkan pada siklus II meningkat menjadi 86,0 dengan kategori sangat baik. Kompetensi pelaksanaan evaluasi pembelajaran pada siklus I mendapat nilai rata-rata sebesar 74,4 dengan kategori cukup sedangkan pada siklus II meningkat menjadi 88,0 dengan kategori sangat baik. Dapat disimpulkan dengan supervisi kunjungan kelas dapat meningkatkan kompetensi guru dalam pembelajaran dengan menerapkan model kooperatif di SD Negeri 011 Pondok Gelugur.

Kata Kunci: supervisi kunjungan kelas, model kooperatif, kompetensi guru

\begin{tabular}{|c|c|c|}
\hline Submitted & Accepted & Published \\
\hline 20 Juni 2019 & 04 November 2019 & 14 November 2019 \\
\hline
\end{tabular}

\begin{tabular}{|l|c|c|c|}
\hline Citation & $:$ & $\begin{array}{r}\text { Nuraisah. (2019). Supervisi Kunjungan Kelas untuk Meningkatkan Kemampuan Guru dalam Mengajar dengan } \\
\text { Menggunakan Model Kooperatif. Jurnal PAJAR (Pendidikan dan Pengajaran), 3(6), 1341-1349. DOI : } \\
\text { http://dx.doi.org/10.33578/pjr.v3i6.7897. }\end{array}$ \\
\hline
\end{tabular}

\section{PENDAHULUAN}

Proses pendidikan dan pembelajran di sekolah dasar (SD) akan berhasil jika kegiatan pembelajaran yang dilakukan dan di kendalikan oleh guru dapat berjalan degngan baik dan guru mampu memberikan layanan pembelajaran yang bermutu dan berkualitas kepada siswa (Syaiful, 2012). Sehingga faktor utama keberhasilan siswa dalam proses pembelajaran sangat ditentukan oleh strategi, model, dan pendekatan pembelajaran yang digunakan oleh guru. Guru dituntut untuk memahami komponen-komponen dasar dalam melaksanakan kegiatan pembelajaran di kelas. Oleh karena itu, guru dituntut untuk paham tentang proses pembelajaran. Pengaturan metode strategi dan kelengkapan dalam pengajaran seperti, silabus, RPP, media, dan evaluasi pembelajaran adalah bagian dari 
kegiatan manajemen pembelajaran yang harus dikuasai oleh setiap guru di sekolah dasar.

Sesuai dengan Sisdiknas (Sistem Pendidikan Nasional) No. 20 Tahun 2003, pasal 39 ayat 1 dan 2 seta dalam Mulyasa (2011:197198), menyatakan bahwa: guru bertugas dalam menjalankan administrasi, pengelolaan, pengembangan, pengawasan, dan pelayanan teknis dalam meningkatkan proses pembelajaran pada suatuan pendidikan. Karena itu guru disebut tenaga profesional yang bertugas merencanakan dan melaksanakan proses pembelajaran, serta menilai dari hasil evaluasi pembelajaran yang telah dilakukan. Ketika seluruh kompetnsi tersebut telah dipenuhi, maka guru tersebut dianggap telah memiliki kinerja yang baik.

Kenyataan di lapangan, berdasarkan hasil observasi peneliti sebagai kepala sekolah, masih banyak kelemahan yang ditemui terutama dalam hal pembuatan rencana pelaksanaan pembelajaran (RPP), Pelaksanaan proses pembelajaran, dan pelaksanaan evaluasi pembelajaran. Tidak sedikit guru-guru hanya mengganti tahun pada RPP yang telah ada atau tidak jarang guru mengambil jalan pintas dengan cara membayar orang untuk membuatkan perangkat pembelajarannya, tidak berpariatifnya guru dalam melakasanaka proses pembelajaran sehingga di dalam proses pembelajaran siswa terlihat bosan dan terkesan pasif dalam pembelajaran. Hal ini membuktikan masih kurangnya kinerja guru dalam melaksanakan tugas-tugasnya sebagai pendidika yang profesional.

Dilihat dari hasil penilaian Kinerja Guru Kelas di SD Negeri 011 Pondok Gelugur Air Molek didapat hasil sebagai berikut ini:

Tabel 1. Rekapitulasi Penilaian Kinerja Guru SD Negeri 011 Pondok Gelugur
\begin{tabular}{cccc}
\hline No & Indikator Kinerja Guru & Nilai Kinerja & Kategori NIlai \\
\hline 1 & Perencanaan Pembelajaran & 53,3 & Sedang \\
\hline 2 & Pelaksanaan Kegiatan Pembelajaran & 66.6 & Cukup \\
\hline 3 & Evaluasi Pembelajaran & 60 & Sedang \\
\hline Rata-rata Nilai & \multicolumn{3}{c}{$\mathbf{5 9 . 9}$} \\
\hline Kategori Nilai & \multicolumn{3}{c}{ Sedang } \\
\hline
\end{tabular}

Dari analisis data tabel 1 di atas menunjukkan bahwa hasil penilaian kinerja guru secara rata-rata menunjukkan nilai 59.9 dengan kategori sedang. Data ini membuktikan bahwa kompetensi guru kelas masih rendah. Melihat kenyataan ini, maka perlu adanya upaya agar kompetensi guru dapat ditingkatkan. Salah satunya dengan menggunakan supervisi kunjungan kelas dengan menggunakan metode kooperatif.

Salah satu peranan supervisi ini adalah memberikan bimbingan dan pembinaan terhadap

\section{KAJIAN TEORETIS}

Sagala (Hadis, 2010) mengartikan supervisi kunjungan kelas merupakan usaha untuk memperbaiki situasi pembelajaran atau sebagai bantuan bagi guru dalam mengelola pembelajaran untuk membantu siswa agar lebih baik dalam belajar. Supervisi juga dapat diartikan sebagai guru. Ngalim Purwanto (2009), Kimball (1967) mengemukakan bahwa supervisi merupakan serangakain kegiatan membina yang terencana untuk membantu guru dalam melakukan pekerjaan mereka secara efektif serta membatu guru membentuk situasi pembelajaran yang lebih baik. Dengan penerapan ini diharapkan guru dalam melaksanakan tugasnya sehari-hari yang meliputi, kegiatan merencanakan, melaksanakan memberikan evaluasi serta memamfaatkan hasil evaluasi sebagai tindak lanjut dapat berjalan dengan baik

bantuan dari kepala sekolah yang tertuju untuk perkembangan kepemimpinan guru-guru dan personil sekolah lainnya dalam mencapai tujuantujuan pendidikan. Bantuan tersebut dapat berupa dorongan, bimbingan, dan kesempatan bagi pertumbuhan keahlian dan kecakapan guru-guru, 
seperti bimbingan dalam usaha dan pelaksanaan pembaharuan-pembaharuan dalam pendidikan.

Ciri-ciri supervisi kunjungan kelas Menurut Pidarta (Prabowo, 2016) ada 5 karakteristik, yaitu: 1) Kunjungan dapat dilakukan dalam waktu singkat 5 s.d 10 menit untuk satu kelas. 2) Bisa juga mengunjungi beberapa kelas dalam satu hari. 3) Supervisor berpartisipasi dalam proses pembelajaran. 4) Supervisor dapat membantu atau menolong guru dalam proses

\section{METODE PENELITIAN}

Penelitian ini dilaksanakan di SD Negeri 011 Pondok Gelugur. Subjek penelitian ini adalah semua guru yang berada di SD Negeri 011 Pondok Gelugur yang berjumlah 6 orang guru.

Jenis penelitian yang akan dilaksanakan adalah Penelitian Tindakan Sekolah (PTS) yang terfokus dalam upaya merubah kondisi nyata terkini kearah yang diharapkan (improvement oriented) (Herlina, 2018). Penelitian ini akan dilaksanakan dalam dua siklus. Pada siklus pertama setiap guru merancang RPP yang akan ditampilkan beserta evaluasi dalam pelaksanaan proses pembelajara. Penampilan guru tersebut diobservasi dan dinilai secara bersama. Hasil observasi dan penilaian tersebut dijadikan bahan untuk melakukan refleksi. Hasil refleksi siklus pertama dijadikan acuan untuk perumusan RPP pada pelaksanaan pembelajaran siklus ke dua.

\section{Analisis Data}

Analisis data dilakukan terhadap data yang telah direduksi baik data perencanaan, pelaksanaan, maupun data evaluasi. Analisis data pembelajaran yang dilakukan. 5) Pada saat-saat tertentu supervisor juga menolong siswa yang menghadapi kesulitan dalam pembelajaran. Setelah kunjungan kelas selesai, selanjutnya diadakan pertemuan balikan antara supervisor dengan guru yang bersangkutan. Supervisor memberikan saran atau nasihat yang diperlukan, guru dapat mengajukan pendapat serta usul-usul yang konstruktif demi perbaikan proses belajar mengajar selanjutnya.

dilakukan dengan cara terpisah-pisah pada perencanaan, pelaksanaan, dan data evaluasi. Hal ini dimaksudkan agar dapat ditemukan berbagai informasi yang spesifik dan terfokus pada berbagai informasi yang mendukung dan yang menghambat pelaksanaan kegiatan. Dengan demikian pengembangan dan perbaikan atas berbagai kekurangan dapat dilakukan tepat pada aspek yang bersangkutan.

Sedangkan model analisis data kuantitatif yaitu terhadap hasil perolehan yang dicapai guru dalam melaksanakan kegiatan, mengacu pada penilaian keberhasilan supervisi kunjungan kelas, dengan rumus sebagai berikut:

Nilai Akhir $=\frac{\text { Skor Perolehan }}{\text { Skor Maksimal }} 100$

(adaptasi dari Sungkem, 2016)

Sedangkan deskripsi kriteria hasil yang diperoleh yaitu :

Tabel 2. Kategori Pencapaian Hasil Penelitian

\begin{tabular}{cc}
\hline Nilai Akhir & Kategori \\
\hline $85-100$ & Sangat Baik \\
\hline $75-84$ & Baik \\
\hline $60-74$ & Cukup \\
\hline $50-59$ & Kurang \\
\hline $0-40$ & Sangat Kurang \\
\hline
\end{tabular}

(adaptasi dari Juwariyah, 2018)

Hasil analisa terhadap pelaksanaan penelitian dalam meningkatkan kompetensi guru dapat dikatakan berhasil apabila guru setelah dilakukan observasi dan penilaian terhadap 
perumusan RPP, pelaksanaan proses pembelajaran, dan pelaksanan evaluasi pembelajaran mendapatkan nilai $\geq 75$ atau

\section{HASIL DAN PEMBAHASAN Hasil Penelitian}

Pelaksanaan penelitian mengupayakan peningkatan kompetensi guru, terutama dalam menyusun Rencana Pelaksanaan Pembelajaran (RPP), melaksanakan proses pembelajaran, dan melaksanakan evaluasi pembelajaran. Strategi yang digunakan dalam meningkatkan kompetensi guru ini adalah menggunakan model Kooperatif. Pelaksanaan kegiatan ditujukan pada 6 orang guru di SD Negeri 011 Pondok Gelugur. Kegiatan dilaksanakan pada semester I Tahun Pelajaran 2018/2019. Dalam pelaksanaan penelitian ini, minimal berada pada kategori baik (Hasniwati, 2019).

Tabel 3. Rekapitulasi Penilaian RPP Guru SD Negeri 011 Pondok Gelugur Siklus I

\begin{tabular}{|c|c|c|c|c|c|c|c|c|c|}
\hline \multirow[t]{2}{*}{ No } & \multirow[t]{2}{*}{ Aspek yang Dinilai } & \multicolumn{6}{|c|}{ Nilai Guru } & \multirow[t]{2}{*}{ Rata-rata } & \multirow[t]{2}{*}{ Kategori } \\
\hline & & 1 & 2 & 3 & 4 & 5 & 6 & & \\
\hline 1 & $\begin{array}{l}\text { Kesesuaian } \\
\text { kelengkapan komponen } \\
\text { RPP }\end{array}$ & 88 & 89.3 & 72.3 & 67.8 & 80 & 77.4 & 79.1 & Baik \\
\hline 2 & $\begin{array}{l}\text { Kesesuian antar } \\
\text { komponen dalam RPP }\end{array}$ & 78.6 & 77.4 & 77.8 & 67.8 & 67.8 & 74.3 & 74.0 & Cukup \\
\hline 3 & $\begin{array}{ll}\text { Kelayakan } & \text { Tujuan } \\
\text { Pembelajaran } & \\
\end{array}$ & 67.8 & 72.3 & 77.4 & 72.3 & 74.3 & 66.8 & 71.8 & Cukup \\
\hline 4 & $\begin{array}{l}\text { Kesesuaian Perumusan } \\
\text { Tujuan pembelajaran }\end{array}$ & 74.3 & 77 & 67.8 & 73.3 & 77 & 75 & 74.1 & Cukup \\
\hline 5 & $\begin{array}{l}\text { Kelayakan Pemilihan } \\
\text { dan Pengorganisasian } \\
\text { materi ajar }\end{array}$ & 72.3 & 72.3 & 74.3 & 88 & 72.3 & 65 & 74.0 & Cukup \\
\hline 6 & $\begin{array}{l}\text { Kelayakan Pelaksanaan } \\
\text { Kegiatan Pembelajaran }\end{array}$ & 73.3 & 66.8 & 65 & 65 & 66.8 & 67.8 & 67.5 & Cukup \\
\hline 7 & $\begin{array}{l}\text { Kesesuaian Pemilihan } \\
\text { sumber belajar }\end{array}$ & 66.8 & 88 & 77 & 72.3 & 65 & 65 & 72.4 & Cukup \\
\hline \multicolumn{8}{|c|}{ Nilai Rata- rata } & 73.3 & Cukup \\
\hline
\end{tabular}

Berdasarkan data pada tabel 3 di atas, hasil penilaian terhadap Rencana Pelaksanaan Pembelajaran (RPP) siklus I, diperoleh hasil penilaian RPP guru berada pada rentang penilaian 67.5 s.d. 79 dengan kategori cukup dan baik. Pada aspek penilaian kesatu, rata-rata guru memperoleh penilaian sebesar 79.1 kategori baik. Pada aspek penilaian kedua dan kelima memperoleh penilaian sebesar 74.0 kategori penulis sebagai peneliti langsung bertindak sebagai narasumber dalam upaya memeberikan perluasan wawasan terhadap guru, selain itu juga berperan sebagai pengamat dan observer dari pelaksanaan rangkaian kegiatan penelitian.

\section{Menyusun \\ Rencana \\ Pembelajaran (RPP) Siklus I}

Pelaksanaan

Berikut akan dipaparkan hasil penilaian terhadap RPP yang dilakukan oleh observer terhadap 6 buah RPP yang telah dirakum dari instrument penilaian RPP siklus I seperti pada tabel 3 berikut: 
Tabel 4. Rekapitulasi Penilaian RPP Guru SD Negeri 011 Pondok Gelugur Siklus I

\begin{tabular}{clcccccccc}
\hline No & Aspek yang Dinilai & \multicolumn{7}{c}{ Nilai Guru } & \multicolumn{2}{c}{ Rata-rata } & Kategori \\
\cline { 2 - 7 } & $\mathbf{1}$ & $\mathbf{2}$ & $\mathbf{3}$ & $\mathbf{4}$ & $\mathbf{5}$ & $\mathbf{6}$ & & \\
\hline 1 & $\begin{array}{l}\text { Kesesuaian } \\
\text { kelengkapan komponen } \\
\text { RPP }\end{array}$ & 88 & 89.3 & 89 & 92.4 & 87.3 & 90 & 89.3 & Sangat Baik \\
\hline 2 & $\begin{array}{l}\text { Kesesuian antar } \\
\text { komponen dalam RPP }\end{array}$ & 95 & 87.8 & 88 & 77 & 89.3 & 89 & 87.7 & Sangat Baik \\
\hline 3 & $\begin{array}{l}\text { Kelayakan Tujuan } \\
\text { Pembelajaran }\end{array}$ & 89.5 & 87.8 & 83.3 & 75 & 92.4 & 75 & 83.8 & Sangat Baik \\
\hline 4 & $\begin{array}{l}\text { Kesesuaian Perumusan } \\
\text { Tujuan pembelajaran }\end{array}$ & 83.3 & 92.4 & 89 & 89.3 & 89.3 & 80 & 87.2 & Sangat Baik \\
\hline 5 & $\begin{array}{l}\text { Kelayakan Pemilihan } \\
\text { dan Pengorganisasian } \\
\text { materi ajar }\end{array}$ & 89 & 89 & 89.5 & 90 & 89.3 & 89 & 89.3 & Sangat Baik \\
\hline 6 & $\begin{array}{l}\text { Kelayakan Pelaksanaan } \\
\text { Kegiatan Pembelajaran }\end{array}$ & 84 & 89.3 & 90 & 88 & 88 & 84 & 87.2 & Sangat Baik \\
\hline 7 & $\begin{array}{l}\text { Kesesuaian Pemilihan } \\
\text { sumber belajar }\end{array}$ & 89.5 & 90 & 87.3 & 89 & 87.3 & 87.3 & 88.4 & Sangat Baik \\
\hline & & Nilai Rata- rata & & & & 87.6 & Sangan Baik \\
\hline
\end{tabular}

Berdasarkan data pada tabel 4 di atas, hasil penilaian terhadap Rencana Pelaksanaan Pembelajaran (RPP) siklus II, diperoleh hasil penilaian RPP guru berada pada rentang penilaian 83.8 s.d. 89.3 dengan kategori sangat baik. Pada aspek penilaian kesatu, rata-rata guru memperoleh penilaian sebesar 89.3 kategori sangat baik. Pada aspek penilaian kedua memperoleh penilaian sebesar 87.7 kategori sangat baik. Pada aspek ketiga memperoleh penilaian sebesar 83.8 kategori sangat baik. Pada aspek penilaian keempat dan enam memperoleh penilaian sebesar 87.2 kategori sangat baik. Aspek penilaian kelima memperoleh penilaian sebesar 89.3 kategori sangat baik, dan aspek peneilaian ketujuh memperoleh penilaian sebesar 88.4 kategori sangat baik. Sedangkan untuk rata- rata penilaian guru sebesar 87.6 kategori sangat baik.

Dari uraian penilaian terhadap RPP diatas dapat disimpulkan bahwa, dengan pelaksanaan supervisi kunjungan kelas dapat meningkatkan kompetensi guru dalam membuat RPP model kooperatif.

\section{Pengamatan Pelaksanaan Proses Pembelajaran}

Berikut dipaparkan hasil observasi dan penilaian terhadap pelaksanaan proses pembelajaran yang dilaksanakan oleh 6 orang guru dengan menerapkan model pebelajaran kooperatif yang dirangkum dari lembar observasi yang dilaksanakan oleh pengamat seperti terlihat pada tabel 5 berikut ini: 
Tabel 5. Rekapitulasi Lembar Penilaian Pelaksanaan Proses Pembelajaran Siklus I

\begin{tabular}{|c|c|c|c|c|c|c|c|c|c|}
\hline \multirow[t]{2}{*}{ No } & \multirow[t]{2}{*}{ Aspek yang Dinilai } & \multicolumn{6}{|c|}{ Nilai Guru } & \multirow[t]{2}{*}{ Rata-rata } & \multirow[t]{2}{*}{ Kategori } \\
\hline & & 1 & 2 & 3 & 4 & 5 & 6 & & \\
\hline 1 & $\begin{array}{l}\text { Kesesuaian Kegiatan } \\
\text { Pendahuluan }\end{array}$ & 81.4 & 72.4 & 89 & 73.4 & 87.3 & 81.4 & 80.8 & Baik \\
\hline 2 & $\begin{array}{l}\text { Kesesuaian } \\
\text { Inti, yegiatan } \\
\text { kegiatan : } \\
\text { Elaborasi, eksplorasi, } \\
\text { konfirmasi, } \\
\text { model/strategi, } \\
\text { media/sumber } \\
\text { pembelajaran, serta } \\
\text { penggunaan bahasa }\end{array}$ & 72.4 & 77 & 77.5 & 67.5 & 77 & 69.6 & 73.5 & Cukup \\
\hline 3 & $\begin{array}{l}\text { Kesesuaian Kegiatan } \\
\text { Penutup }\end{array}$ & 69.6 & 74.6 & 72.4 & 74.6 & 67.5 & 73.4 & 72.0 & Cukup \\
\hline \multicolumn{8}{|c|}{ Rata-rata } & 75.4 & Baik \\
\hline
\end{tabular}

Berdasarkan data pada tabel 5 di atas, hasil penilaian terhadap Pelaksanaan Proses Pembelajaran menggunakan model kooperatif di siklus I mendapt nilai rata-rata sebesar 75.4 dengan kategori baik. Dilihat dari aspek pertama guru mendapat penilaian sebesar 80.8 dengan kategori baik. Pada aspek kedua, guru mendapat penilaian sebesar 73.5 dengan kategori cukup, dan pada aspek ketiga guru mendapat penilaian sebesar 72.0 dengan kategori cukup.

Sedangkan hasil penelitiaan terhadap proses pembelajaran siklus II dapat dilihat pada tebel 6 berikut ini:

Tabel 6. Rekapitulasi Lembar Penilaian Pelaksanaan Proses Pembelajaran Siklus II

\begin{tabular}{|c|c|c|c|c|c|c|c|c|c|}
\hline \multirow[t]{2}{*}{ No } & \multirow[t]{2}{*}{ Aspek yang Dinilai } & \multicolumn{6}{|c|}{ Nilai Guru } & \multirow[t]{2}{*}{ Rata-rata } & \multirow[t]{2}{*}{ Kategori } \\
\hline & & 1 & 2 & 3 & 4 & 5 & 6 & & \\
\hline 1 & $\begin{array}{ll}\text { Kesesuaian } & \text { Kegiatan } \\
\text { Pendahuluan } & \\
\end{array}$ & 91.6 & 92.3 & 87.2 & 83.8 & 92.4 & 89 & 89.4 & Sangat Baik \\
\hline 2 & $\begin{array}{l}\text { Kesesuaian Kegiatan } \\
\text { Inti, yang meliputi } \\
\text { kegiatan : } \\
\text { Elaborasi, eksplorasi, } \\
\text { komfirmasi, } \\
\text { model/strategi, } \\
\text { media/sumber } \\
\text { pembelajaran, serta } \\
\text { penggunaan bahasa }\end{array}$ & 83.3 & 87.7 & 90 & 89.3 & 83.8 & 87.2 & 86.9 & Sangat Baik \\
\hline 3 & $\begin{array}{ll}\text { Kesesuaian } & \text { Kegiatan } \\
\text { Penutup } & \\
\end{array}$ & 81.1 & 92.4 & 77 & 75 & 89.3 & 75 & 81.6 & Baik \\
\hline \multicolumn{8}{|c|}{ Rata-rata } & 86.0 & Sangat Baik \\
\hline
\end{tabular}

Berdasarkan data pada tabel 6 di atas, hasil penilaian terhadap pelaksanaan proses pembelajaran menggunakan model kooperatif di siklus II mendapat nilai rata-rata sebesar 86.0 dengan kategori sangat baik. Dilihat dari aspek pertama guru mendapat penilaian sebesar 89.4 dengan kategori sangat baik. Pada aspek kedua, guru mendapat penilaian sebesar 86.9 dengan kategori sangat baik, dan pada aspek ketiga guru mendapat penilaian sebesar 81.6 dengan kategori 
baik.

Dari uraian penilaian terhadap proses pembelajaran diatas dapat disimpulkan bahwa, dengan pelaksanaan kooperatif dapat meningkatkan kompetensi guru dalam proses pembelajaran.

1. Pelaksanaan Evaluasi Pembelajaran
Evaluasi pembelajaran dilakukan sejalan dengan pelaksanaan proses pembelajaran, pada tahap ini dilaksanakan pengamatan terhadap pelaksanaan evaluasi dilihat dari penampilan semua guru yang menjadi subjek penelitian, adapun hasil pengamatan dijabarkan dalam tabel 7 berikut ini:

Tabel 7. Lembar Penilaian Pelaksanaan Evaluasi Hasil Belajar Guru Siklus I

\begin{tabular}{|c|c|c|c|c|c|c|c|c|c|}
\hline \multirow[t]{2}{*}{ No } & \multirow[t]{2}{*}{ Aspek yang Dinilai } & \multicolumn{6}{|c|}{ Nilai Guru } & \multirow[t]{2}{*}{ Rata-rata } & \multirow[t]{2}{*}{ Kategori } \\
\hline & & 1 & 2 & 3 & 4 & 5 & 6 & & \\
\hline 1 & $\begin{array}{l}\text { Kesesuaian dengan } \\
\text { Komponen Penilaian }\end{array}$ & 68.2 & 75 & 69.6 & 73.4 & 72.4 & 73.3 & 72.0 & Cukup \\
\hline 2 & $\begin{array}{l}\text { Kesesuaian dengan } \\
\text { Rumusan Penilaian }\end{array}$ & 73.3 & 78.6 & 77.4 & 67.8 & 78.6 & 77 & 75.5 & Baik \\
\hline 3 & $\begin{array}{l}\text { Kesesuaian dengan } \\
\text { Prosedur Penilaian }\end{array}$ & 72.3 & 67.8 & 80 & 88 & 69.6 & 77.4 & 759 & Baik \\
\hline & & & ata & & & & & 74.4 & Cukup \\
\hline
\end{tabular}

Berdasarkan data pada tabel 7 di atas, pada pelaksanaan evaluasi pembelajaran siklus I dapat dilihat secara rata-rata memperoleh nilai sebesar 74.4 dengan kategori cukup. Dari 3 aspek penilaian di atas, Aspek kesesuaian dengan komponen penilaian mendapat nilai rata-rata sebesar 70.0 dengan kategori cukup. Aspek kesesuaian dengan rumusan penilaian mendapat nilai rata-rata sebesar 75.5 dengan kategori baik, dan aspek kesesuaian dengan prosesdur penilaian mendapat nilai rata-rata sebesar 75.9 dengan kategori cukup.

Sedangkan hasil penilaian terhadap evaluasi hasil belajar pada siklus II dapat dilihat pada tabel 8 berikut ini:

Tabel 8. Lembar Penilaian Pelaksanaan Evaluasi Hasil Belajar Guru Siklus I

\begin{tabular}{|c|c|c|c|c|c|c|c|c|c|}
\hline \multirow[t]{2}{*}{ No } & \multirow[t]{2}{*}{ Aspek yang Dinilai } & \multicolumn{6}{|c|}{ Nilai Guru } & \multirow[t]{2}{*}{ Rata-rata } & \multirow[t]{2}{*}{ Kategori } \\
\hline & & 1 & 2 & 3 & 4 & 5 & 6 & & \\
\hline 1 & $\begin{array}{l}\text { Kesesuaian dengan } \\
\text { Komponen Penilaian }\end{array}$ & 87.8 & 92.4 & 89 & 90 & 83.3 & 87.7 & 88.4 & Sangat Baik \\
\hline 2 & $\begin{array}{l}\text { Kesesuaian dengan } \\
\text { Rumusan Penilaian }\end{array}$ & 87.7 & 83.3 & 92.4 & 89 & 83.3 & 80 & 86.0 & Sangar Baik \\
\hline 3 & $\begin{array}{l}\text { Kesesuaian dengan } \\
\text { Prosedur Penilaian }\end{array}$ & 89.5 & 87.8 & 92.4 & 89.3 & 89.3 & 90 & 89.7 & Sangat Baik \\
\hline \multicolumn{8}{|c|}{ Rata-rata } & 88.0 & Sangat Baik \\
\hline
\end{tabular}

Berdasarkan data pada tabel 8 di atas, pada pelaksanaan evaluasi pembelajaran siklus II dapat dilihat secara rata-rata memperoleh nilai sebesar 88.0 dengan kategori sangat baik. Dari 3 asfek penilaian diatas, Aspek kesesuaian dengan komponen penilaian mendapat nilai rata-rata sebesar 88.4 dengan kategori sangat baik. Aspek kesesuaian dengan rumusan penilaian mendapat nilai rata-rata sebesar 86.0 dengan kategori sangat baik, dan aspek kesesuaian dengan prosesdur penilaian mendapat nilai rata-rata sebesar 89.7 dengan kategori sangat baik.

Dari uraian penilaian terhadap pelaksanaan evaluasi hasil belajar diatas dapat disimpulkan bahwa, pelaksanaan supervisi kunjungan kelas degan menerapkan model pembelajaran kooperatif dapat meningkatkan kompetensi guru dalam pelaksanaan evaluasi 
hasil belajar.

\section{SIMPULAN DAN REKOMENDASI}

Berdasarkan hasil penelitian terhadap peningkatan kompetensi guru dalam pembelajaran dengan menggunakan model kooperatif di SD Negeri 011 Pondok Gelugur, maka dapat peneliti simpulkan beberapa hal sebagai berikut;

1. Dengan pelaksanaan supervisi kunjungan kelas dengan menerapkan model kooperatif dalam menyusun RPP pada siklus I mendapat nilai sebesar 73.3 dengan kategori cukup sedangkan pada siklus II meningkat menjadi 87.6 dengan kategori sangat baik.

2. Dengan pelaksanaan supervisi kunjungan kelas dengan menerapkan model kooperatif dalam pelaksanaan proses pembelajaran pada siklus I mendapat nilai rata-rata sebesar 75.4 kategori baik sedangkan pada siklus II rata-rata penilaian pelaksanaan proses pembelajaran siklus II meningkat menjadi 86.0 dengan kategori sangat baik.

3. Dengan pelaksanaan supervisi kunjungan kelas

\section{DAFTAR PUSTAKA}

Abdul, H. (2010). Manajemen Mutu Pendidikan. Bandung: Alfabeta.

Depdiknas. (2003). Undang-undang RI No.20 tahun 2003. Tentang sistem pendidikan nasional.

Hasniwati. (2019). Penerapan Model Pembelajaran Pictue and Picture untuk Meningkatkan Hasil Belajar IPA Siswa Kelas II A SD Negeri 004 Cendirejo Kecamatan Pasir Penyu Kabupaten Indragiri Hulu. Jurnal PAJAR (Pendidikan dan Pengajaran), 3 (1), 189-196

Herlina. (2018). Meningkatkan Kompetensi Guru dalam Menyusun Model Pembelajaran Melalui Workshop di Sd Negeri 009 Seberang Teluk Kecamatan Kuantan Tengah Kabupaten Kuantan Singingi. Jurnal PAJAR (Pendidikan dan Pengajaran), 2(5), 812-819.

Juwariyah. (2018). Model Pembelajaran Inkuiri untuk Meningkatkan Hasil Belajar IPA Siswa Kelas V SDN 016 Beringin Jaya dengan menerapkan model kooperatif dapat meningkatkan kompetensi guru dalam pelaksanaan evaluasi pembelajaran. pada siklus I mendapat nilai rata-rata sebesar 74.4 dengan kategori cukup sedangkan pada siklus II meningkat menjadi 88.0 dengan kategori sangat baik.

Berdasarkan simpulan hasil penelitian diataas, peneliti memberikan saran yait; model kooperatif hendaknya digunakan dalam upaya peningkatan kompetensi guru dalam melaksanakan proses pembelajaran di kelas, terutama dalam peningkatan kemampuan guru dalam menyusun RPP, melaksanakan proses pembelajaran, dan melaksanakan evaluasi pembelajaran. Pelaksanaan model kooperatif dapat dilaksanakan untuk semua guru dan semua mata pelajaran. Untuk peneliti selanjutnya, hasil penelitian ini dapat dijadikan referensi dalam melaksanakan penelitian berikutnya.

Kecamatan Singingi Hilir Kabupaten Kuantan Singingi. Jurnal PAJAR (Pendidikan dan Pengajaran), 2(5), 725730.

Kimball,W. (1967). Supervison for Better Schools.Englewood Cliffs. New Jersey: PrenticeHall.

Mulyasa, E. (2012). Kurikulum Berbasis Kompetensi: Konsep, Karakteristik, dan Implementasi. Bandung: PT Remaja Rosdakarya.

Purwanto, N. (2009). Prinsip-Prinsip dan Teknik Evaluasi Pengajaran. Bandung : Rosdakarya.

Prabowo, S., \& Yoga, D.S. (2016). Supervisi Kunjungan Kelas Sebagai Upaya Membina Profesional Guru SLTP/SLTA. Jurnal Sosial Humaniora, 9(1), 96-113.

Syaiful, S. (2012). Supervisi Pembelajaran. Bandung : Alfabeta.

Sungkem. (2016). Penerapan Strategi Inkuiri Biologi untuk Meningkatkan Hasil Belajar 
IPA Siswa Kelas III SD Negeri 010 Silikuan Hulu Kecamatan Ukui Kabupaten Pelalawan. Primary: Jurnal Pendidikan Guru Sekolah Dasar, 5(2), 249-258. 